\title{
CORRUPÇÃO E DEMOCRACIA ${ }^{1,2}$
}

\author{
Manoel GonÇalves FerReira Filho*
}

I. Considerações preliminares. II. Caracterização da corrupção política. III. A repressão da corrupção política. IV. A prevenção da corrupção política. V. Observações finais.

\section{Considerações preliminares.}

1. O fenômeno da corrupção é registrado desde a remota antigüidade. Noonan, professor americano que realizou um exaustivo estudo sobre a matéria, assinala que há três mil anos já era ela denunciada ${ }^{3}$. Não é, porém, um fenômeno do passado, nem localizado. Em todos os tempos, lugares e culturas, ela aparece ${ }^{4}$.

Sempre foi ela vista como um mal. E um mal gravíssimo, que solapa os alicerces do Estado e ameaça a sociedade. Assemelha-se à podridão do fruto. É o que assinala a etimologia do termo. Corruptio, em latim, é a explosão do âmago de um fruto, em razão da sua podridão interna.

Assim, o que se encara como corrupção não é apenas uma falta, grave sem

1 Trata-se da palestra introdutória proferida no X Encontro Nacional de Direito Constitucional, sob o patrocínio do Instituto "Pimenta Bueno" - Associaçāo Brasileira dos Constitucionalistas, na Faculdade de Direito da USP, em 4 de Outubro de 2001.

2 Já analisei, com maior extensão, este tema no livro Constituição e Governabilidade, Saraiva, São Paulo, 1995, cap. 10, p. 107 e s.

* Professor Titular de Direito Constitucional da Faculdade de Direito da USP. Doutor honoris causa da Universidade de Lisboa. Doutor pela Universidade de Paris. Ex-Professor visitante da Faculdade de Direito de Aix-en-Provence (França). Membro da Comissão Executiva da Association Internationale de Droit Constitutionnel - AIDC. Presidente do Instituto "Pimenta Bueno" Associação Brasileira dos Constitucionalistas.

3 John T. Noonan, Jr, Bribes, University of California Press, Berkeley, 1987, p. XI e s.

4 No Brasil colonial, no século XVII, já a verberava a Arte de Furtar, de autoria atribuída ao Pe. Antônio Vieira. 
dúvida, mas que não transcende a pessoa que a comete. É uma falta que perverte, e por isso, ameaça o regime, porque solapa os seus fundamentos.

2. A luta contra a corrupção é difícil e não raro frustrante. Isto, por um lado, deriva da variedade de formas com que se oculta, da multiplicidade dos modos em que se manifesta. Certamente, também, pelo fato de que suas raízes se insinuam no cerne da alma humana, pois somente existe ligada a uma fraqueza moral.

3. Na democracia contemporânea, ela é reconhecida como uma ameaça talvez mais grave do que noutros regimes.

Esta democracia, com efeito, se constrói a partir de um modelo ideal elevado, para cujo funcionamento se reclama do homem a virtude. Ao menos era isto que apontava Montesquieu ao considerar exatamente a virtude como o princípio, a mola mestra, da democracia ${ }^{5}$.

Enquanto modelo ideal, a democracia pressupõe que o povo escolha pelo voto os seus representantes, que irão governá-lo. Pretende que nessa escolha o eleitor não leve em conta senão as qualidades do candidato e seu programa de atuação. Reclama que o eleito aja em vista exclusivamente do interesse geral, doa o que doer, custe o que custar. E tanto povo, como governante, nada devem esperar em troca de sua participação, exceto a satisfação do dever cumprido.

É elevado demais o plano? É irrealista?

Talvez o seja, mas é o padrão proposto para a conduta política.

4. Na vida cotidiana das democracias, entretanto, a corrupção se insinua, seja no processo de escolha dos governantes - o processo eleitoral; seja no processo de atuação dos mesmos - o processo governamental.

Esta é a razão básica porque ela é estudada nesta ocasião.

\section{Caracterização da corrupção política.}

5. Que é, porém, corrupção política?

Não é fácil, como parece à primeira vista, apresentar um conceito claro e seguro. Primeiro, porque é diferente a visão das diversas culturas a esse propósito; segundo porque essa visão tem variado com o tempo; terceiro, porque, numa mesma comunidade, numa mesma época, coexistem entre suas classes ou grupos entendimentos diferentes sobre no que ela consiste, e qual a gravidade relativa de cada ato que a configure.

6. Ninguém contestará, no entanto, ser corrupção todo ato que envolver uma retribuição material - essencialmente de dinheiro - o instrumento ou móvel da conduta indevida.

Assim, há corrupção, seja quando se usa desse recurso para a obtenção do poder, seja quanto se utiliza do poder para lograr proveito financeiro. Num caso, o dinheiro - use-se o nome - é meio ilícito para fim lícito, no segundo é o objetivo ilícito de uma conduta. 
7. Há, porém, um outro padrão, mais rigoroso. Segundo este, há corrupção toda vez que o instrumento ou o móvel é uma vantagem - mesmo não monetária indevida. Entretanto, como toda ação política tem como móvel uma "vantagem", seja para o político, seja para o eleitor, seja para um grupo social, não é simples separar o que é "indevido".

Esta última situação nem sempre é fácil de separar, in concreto, de outras condutas que não são condenadas como ilegítimas. Em termos abstratos, talvez seja fácil distinguir as hipóteses e separar o joio do trigo; na prática, a distinção entre o legítimo e o ilegítimo é, não raro, bem esfumada. Não é difícil demonstrá-lo.

8. Considere-se, indo um pouco mais fundo na análise, a corrupção no processo eleitoral.

Sem dúvida, há de reconhecer-se como corrupção a compra de votos, o suborno dos membros de mesas receptoras de votos, ou apuradoras dos resultados. Nisto o elemento dinheiro, atua diretamente.

9. Mas a isto se assimila, por exemplo, o abuso do poder econômico. Este envolve o emprego indevido de recursos monetários, todavia, nesta hipótese, por meio destes se atua apenas indiretamente sobre o processo eleitoral. Com efeito, por meio dos meios financeiros, visa-se a criar um "clima" favorável ao candidato. $\mathrm{E}$, admita-se mais, só o abuso é condenado, não o mero uso do dinheiro na campanha...

Ora, a criação de tal "clima" também resulta de outros meios que não se consideram - pelo menos fora de uma visão rigorista - como "corruptores".

Tenha-se em mente, por exemplo, que esse "clima" pode ser obtido - e quantas vezes o é - pela manipulação das informações pelos meios de comunicação de massa. Ou pela propaganda enganosa (e qual não o é?)...

Será isto substancialmente diferente do abuso de poder econômico? Não perverterá isto também o sentido do voto?

10. Examine-se a corrup̧̧ão no exercício do poder.

Esta é insofismável quando um ato do governante decorre de um "estímulo" que é um "presente" que recebe. Com mais razão ainda, se esse "presente" é contrapartida exigida.

11. Contudo, a situação é pelo menos ambígua, quando o uso do poder se desvia do interesse geral para atender a interesses de grupos ou mesmo a interesses pessoais. Isto é, quando busca favorecer um segmento da sociedade, eventualmente atendendo a suas reivindicações, ou visa a promover o prestígio do governante, ou mesmo a criar a base de sustentação de que este necessita para executar uma política governamental.

Numa visão rígida, o governante que leva uma obra, ou um investimento, para a sua base eleitoral, ou promove uma medida para aumentar sua popularidade, estaria incidindo em corrupção. Da mesma forma, o parlamentar que insere num projeto disposição que beneficia grupo que o prestigia ou apoia, ou obtém do governo o atendimento de uma reivindicação. E neste caso também o governante que o atende, por exemplo para contar no futuro com seu voto nas deliberações congressuais.

Tudo isto, entretanto, não estaria na prática normal do governo democrático, ainda que fugindo ao modelo ideal? 
Com efeito, os eleitores não esperam dos "seus" eleitos o atendimento de suas “justas" demandas? A vitória eleitoral, a obtenção de apoio parlamentar não são condições, numa democracia, para realizar o próprio interesse geral?

12. Confirmam estas observações ser difícil e complexo separar a corrupção de outras condutas políticas que destoam do ideal, se adotada a visão rigorista.

Por isso, parece razoável reservar esse termo para os casos em que a retribuição material está presente, ou, pelo menos, a casos em que a vantagem indevida obtida é análoga a esta.

Estender o conceito até os casos em que uma vantagem não material é o estímulo ou a meta da conduta política, pode coadunar-se com o modelo ideal apontado, mas contraria a natureza - certamente imperfeita - do ser humano (pelo menos desde o pecado original). Atuar na política, sem atender aos "justos" reclamos do eleitorado, ou sem retribuir ao apoio dado ou pretendido, é impossível, sendo o homem como é. Que o modelo abstrato torça o nariz para isso, registre-se; mas sem a atenuação mencionada não haverá democracia, enquanto o homem não se tornar santo.

A corrupção que se há de combater na democracia é aquela que envolve retribuição material. Esta, sim, perverte as suas instituições e seus mecanismos. É a que tem de ser reprimida, é a que deve ser prevenida.

Outras práticas poderão ser a-éticas, não configuram corrupção. Estender a estas o labéu de corrupção é alargar de tal forma o conceito que este se torna impreciso e inútil. Pode servir a objetivos políticos, ou da videodemocracia, foge a um tratamento objetivo da questão.

\section{A repressão da corrupção política.}

13. Não faltam nas Constituições e nas leis normas punindo, e duramente, a corrupção política. Veja-se o caso brasileiro.

Em nível constitucional, por exemplo, - e citando a Carta Magna de 1988 não faltam regras que punem com a perda do mandato a corrupção eleitoral, o abuso de poder econômico (art. 14, §10). Ou sancionam a "improbidade administrativa" do servidor público em geral (art. $37, \S 4^{\circ}$ ). E é crime de responsabilidade do Presidente da República a violação do princípio de "probidade na administração" (art. 85, V), que importa na perda do mandato etc.

14. Em nível infraconstitucional, são punidas como crimes várias práticas, umas que ocorrem no processo eleitoral, outras, na ação governamental, mormente administrativa.

O Código Penal sanciona os delitos denominados contra a Administração Pública (Código Penal, art. 312 e s.): peculato, concussão, corrupção passiva, prevaricação etc.

Igualmente, a legislação eleitoral capitula como criminosas inúmeras condutas que dizem respeito ao processo de escolha dos representantes do povo.

15. Uma coisa, porém, é ter, no corpo do ordenamento, as leis punitivas, outra, dar-lhes efetividade. 
Mesmo nos períodos autoritários, quando se procede ao arrepio das regras do Estado de Direito não se tem logrado êxito na repressão à corrupção. Disto é exemplo o regime militar brasileiro. Este se empenhou na repressão aos "corruptos" (e não só aos "subversivos") sem lograr extirpar a corrupçãó.

Mais difícil ainda é fazê-lo nos períodos de normalidade, em que é preciso provar as acusações, num processo judicial ao qual é inerente o contraditório.

\section{A prevenção da corrupção política.}

16. Há também na Constituição e na lei inúmeras disposições que visam a prevenir a corrupção.

Assim, no plano do processo eleitoral, há todo o rol das inelegibilidades. $\mathrm{Na}$ Constituição vigente, prevê o art. $14, \S 9^{\circ}$ o estabelecimento de "casos de inelegibilidade..., a fim de proteger a probidade administrativa, a moralidade para o exercício do mandato, considerada a vida pregressa do candidato, e a normalidade e legitimidade das eleições, contra a influência do poder econômico ou o abuso do exercício de função, cargo ou emprego na administração direta ou indireta".

A legislação eleitoral, por outro lado, limita as despesas eleitorais e procura assim impedir abusos. Etc.

17. No plano da ação administrativa, não faltam no art. 37 da Constituição normas que visam a prevenir a corrupção. Assim, por exemplo, o inciso XXI faz obrigatória a licitação pública, para a contratação de obras, serviços, compras e alienações etc.

Desnecessário até é acrescentar que a legislação infraconstitucional prevê inúmeras formalidades, procedimentos e controles com o fito de prevenir a corrupção.

18. Entretanto, é triste mas necessário reconhecer a pouca eficácia de tais normas. Certamente, essas normas todas não tem logrado um êxito cabal.

É preciso, contudo, ter presente, que isto igualmente ocorre no estrangeiro. Considere-se o exemplo estrangeiro, por exemplo da Alemanha, em que o financiamento público das eleições foi estabelecido por meio de um sistema sofisticado, tendo em mira prevenir a corrupção e os abusos. Lá é recente o escândalo envolvendo o chanceler Kohl... Da mesma forma, casos notórios de corrupção administrativa têm ocorrido no Japão, na Holanda, na França etc.

\section{Observações finais.}

19. Realmente, não logram essas medidas, entretanto, o efeito dissuasório que delas se espera. A corrupção persiste apesar dessas todas sanções, ou disposições preventivas.

Por que? 
20. Uma razão certamente é a de que as tentações são fortes e, sobretudo, tão mais fortes quão mais alto se acha na escala do poder aquele que é tentado.

Contemporaneamente, as grandes obras públicas, que o Estado atribui a este ou àquele, ainda que em procedimentos formais de índole do tipo licitação, são uma ocasião ímpar de corrupção. Um contrato administrativo pode fazer a fortuna do contratado e, por outro lado, a contrapartida pouco ou nada lhe custa, porque pode ser acrescentada ao preço da obra... Sem dúvida, está aí a razão de que, no Estado desenvolvimentista, em geral ocorrem surtos de corrupção ${ }^{7}$.

21. Outra, que os "poderosos" têm meios de obstar à apuração dos fatos ou de cercear o processo punitivo. Inclusive contam frequientemente com a solidariedade dos "colegas". E como o que se elege ipso facto se torna "poderoso", muitos entendem que vale o risco.

22. Por outro lado, o processo eleitoral apaixona mesmo os governantes mais sérios. $\mathrm{O}$ insucesso eleitoral, seu ou de seus aliados, configura-lhes o fracasso, que é preciso evitar de qualquer modo, até pelo modo mais irregular. $\mathrm{O}$ administrador mesmo probo, em vista disto, escorrega não raro na improbidade para vencer a eleição: o fim elevado - o bem comum - não justificaria os meios?

23. Não se pode, entretanto, descurar um elemento, talvez o mais importante. Trata-se do aspecto moral, individual, $\operatorname{sim}^{8}$, mas principalmente coletivo.

Claro que a corrupção depende, numa micro-análise, do padrão moral do indivíduo. Mais importante, contudo, é levar em conta o padrão moral da coletividade. Pareto observa, certamente com alguma razão, haver uma correlação entre o nível geral de moralidade da população e a dos políticos'.

Com efeito, numa comunidade em que o cidadão em geral - e é ele o soberano e o eleitor - frequientemente busca vantagens especiais para si e os seus, ou para grupos de interesse a que pertença não se há de esperar que o político não o faça. Ou não procure atendê-los. Mesmo porque se heroicamente não o fizer, sua carreira será curta.

Ora, a formação moral, individual ou coletiva, escapa da ação do direito. É questão de civilização, de educação, de religião...

Por isso, cumpre acentuar que a prevenção e o combate à corrupção, se não dispensam leis, reclamam mais que meras leis.

24. A complexidade da questão da corrupção justifica as dificuldades que encontra em face dela o direito constitucional. A este pertence, de fato, definir as normas que devem preveni-la no plano político, apurar sua ocorrência e punir os que nela incidem, quer na disputa pelo Poder, quer no exercício deste, tarefa espinhosa e inglória.

7 Samuel P. Huntington, A ordem política nas sociedades em mudança, trad. port., Ed. ForenseUniversitária, São Paulo, 1975, p. 72 e s.

8 É de lembrar-se o registro de Ovídio: "Video meliora proboque, deteriora sequor".

9 Traité de Sociologie Générale, trad. fr., Droz, Genebra, 3 ed., 1968, $\mathrm{n}^{\circ}$ 2267: "Lá onde (a população) é mais honesta ou menos honesta, acha-se também um governo mais honesto ou menos honesto". 